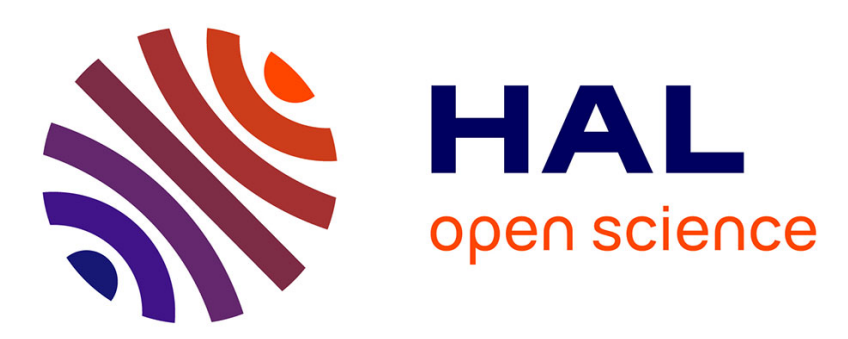

\title{
Nonlinear Delayed Differential Optical Phase Feedback For High Performance Chaos Communications
}

\author{
M. Jacquot, R. Lavrov, L. Larger
}

\section{To cite this version:}

M. Jacquot, R. Lavrov, L. Larger. Nonlinear Delayed Differential Optical Phase Feedback For High Performance Chaos Communications. Conference on Lasers and Electro-Optics CLEO/Quantum Electronics and Laser Science Conference (QELS), May 2010, San Jose, United States. 10.1364/CLEO.2010.CFC6 . hal-00586336

\section{HAL Id: hal-00586336 https://hal.science/hal-00586336}

Submitted on 23 Apr 2021

HAL is a multi-disciplinary open access archive for the deposit and dissemination of scientific research documents, whether they are published or not. The documents may come from teaching and research institutions in France or abroad, or from public or private research centers.
L'archive ouverte pluridisciplinaire HAL, est destinée au dépôt et à la diffusion de documents scientifiques de niveau recherche, publiés ou non, émanant des établissements d'enseignement et de recherche français ou étrangers, des laboratoires publics ou privés. 


\title{
Nonlinear Delayed Differential Optical Phase Feedback For High Performance Chaos Communications
}

\author{
Maxime Jacquot, Roman Lavrov, Laurent Larger \\ University of Franche-Comte, FEMTO-ST Institute / Optics Dept. \\ 16 route de Gray 25030 Besançon cedex, France \\ mjacquo6@univ-fcomte.fr
}

\begin{abstract}
We report on the latest development in electro-optic chaos communications intended for physical layer optical data protection. The nonlinear delayed feedback scheme makes use of the optical phase as the dynamical variable exhibiting a high complexity broadband chaos. The proposed setup was found to be a superior alternative approach to the most popular way in Optics to generate chaos, the feedback laser dynamics. We report unprecedented performances in terms of bit rate and transmission quality (up to $10 \mathrm{~Gb} / \mathrm{s}$, with nearly error free transmission over more than $100 \mathrm{~km}$, without digital error correction), both in laboratory and field experiments.
\end{abstract} (C)2010 Optical Society of America

OCIS codes: (060.4785) Optical security and encryption, (190.3100) Instabilities and chaos, (060.4510) Optical communications, (060.1660) Coherent communications, (060.5060) Phase modulation

\section{Introduction}

Chaotic waveforms have attracted much positive attention in the past 20 years for their potential use in secured communications at the physical layer, after the demonstration of the phenomenon of chaos synchronization [1]. This research area was intensively investigated in Optics for two practical reasons: only optical physical systems can provide potentially ultra-fast real time analogue processing which can not be achieved by conventional algorithmic encryption techniques; and Optics also easily allows for the intrinsic capability to perform nonlinear delay dynamical systems, which are well known to provide high complexity and infinite dimensional chaotic dynamics that are difficult to (crypt-)analyze. Among the latter class of nonlinear dynamics, one can find essentially two competitive approaches in the literature. The most common [2-9] one is based on the nonlinear rate equation of a laser, additionally subjected to an external (optical or optoelectronic) feedback. Another approach $[9,10]$ to which the reported results belong, is based on the principle of the all-optical Ikeda ring cavity, however performed experimentally through optoelectronic or electro-optic feedback. We have recently developed a powerful variation of the Ikeda dynamics through the principle of a temporally non-local non linear delayed feedback, which is implemented via coherent DPSK modulation techniques [11]. The high reliability of this electro-optic phase chaos architecture allowed to establish, as far as we know, state of the art performances in optical chaos communications in terms of bit rate of a chaos embedded digital message, chaos synchronization and chaos decoding quality. We will report both laboratory and field experiments performed at $10 \mathrm{~Gb} / \mathrm{s}$ up to $120 \mathrm{~km}$.

\section{Setup and Principles}

The emitter and receiver setup is depicted in Fig.1. It consists of 5 sub-systems performing together a point-to-point optical communication link which can be secured by a chaotic optical phase modulation. The first sub-system is a standard DPSK modulator performed with a conventional DFB laser and an external phase modulator driven by the adequate signal for binary data DPSK modulation. The second subsystem also belongs to the emitter, and is intended to hide the initial DPSK modulation into a chaotic optical phase modulation. This phase chaos generator was investigated in [11], and makes use of an imbalanced interferometer -imbalancing independent of the message bit rate-, in order to achieved a nonlinear transformation which is non-local in time. Chaotic oscillations are obtained when the phase modulation is performed faster than the interferometer imbalancing, and with a large enough phase modulation ( $>\pi$, strong feedback gain). This phase chaos generator involves a dual time delay feedback architecture (time imbalancing $\delta T$ of a few $100 \mathrm{~s}$ ps, and total feedback delay $T$ of several $10 \mathrm{~s}$ of ns), combined with a broadband optoelectronic feedback (bandpass filtering from the photodiode to the phase modulator electrode, with a low cut-off response time of few $\mu \mathrm{s}$, down to a high cut-off response time of a few $10 \mathrm{~s} \mathrm{ps).} \mathrm{This} \mathrm{leads} \mathrm{to} \mathrm{a} \mathrm{strong} \mathrm{multiple} \mathrm{time} \mathrm{scale} \mathrm{dynamical} \mathrm{system,} \mathrm{capable}$ of broadband chaotic oscillations covering 6 orders of magnitude, from a few $10 \mathrm{~s} \mathrm{kHz}$ up to more than $10 \mathrm{GHz}$.

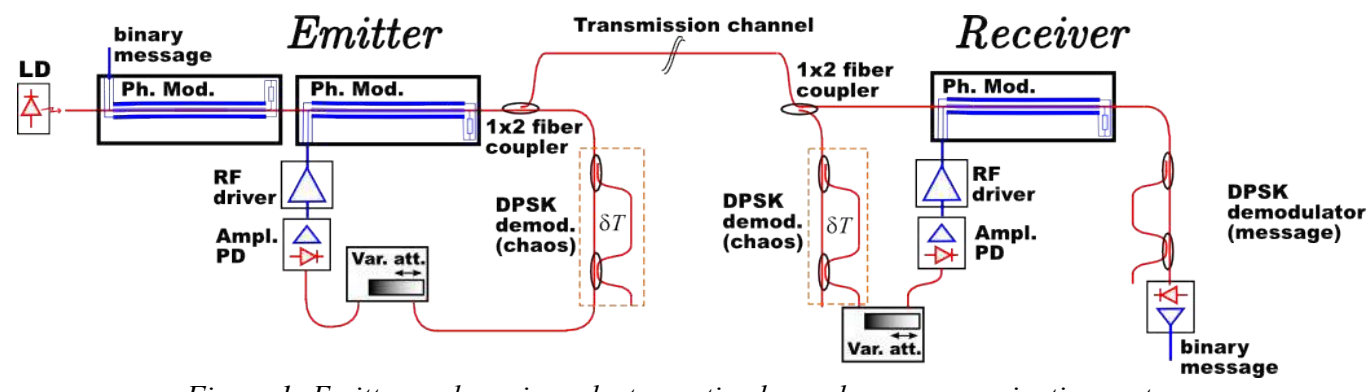

Figure 1: Emitter and receiver electro-optic phase chaos communication system.

The third sub-system is a standard transmission fiber channel, with EDFAs and dispersion compensation modules. The fourth subsystem is designed to replicate the emitter chaotic phase modulation, with an opposite sign. The input light beam is thus electrooptically processed in order to cancel the chaotic optical phase fluctuations masking the DPSK message modulation. At the receiver phase modulator output, we expect to have the DPSK modulation of the message only, if proper phase chaos cancellation is achieved. The last sub-system is intended to perform a standard DPSK demodulation. 


\section{Chaos communications results}

The previously described transmission system was designed and tested in laboratory and field experiments. Excellent phase chaos cancellation has been obtained, as illustrated by Fig.2 left, with more than $10 \mathrm{~dB}$ chaotic optical spectrum cancellation, over more than $10 \mathrm{GHz}$. This performance allowed to hide a DPSK signal up to $10 \mathrm{~Gb} / \mathrm{s}$. Dispersion compensation (DC) has been found to be a critical issue in order to maintain the chaos cancellation capability, even after a few kilometers of transmission fiber channel. However, standard DC modules were efficient enough. Standard EDFAs combined with channel filtering before decoding were also efficient enough to recover nearly similar performances after more than $100 \mathrm{~km}$, compared to the back-to-back situation. Depending on the chaotic embedding strength, $10^{-9}$ bit error rate could have been achieved, as illustrated by the eye diagrams in Fig. 2 right.
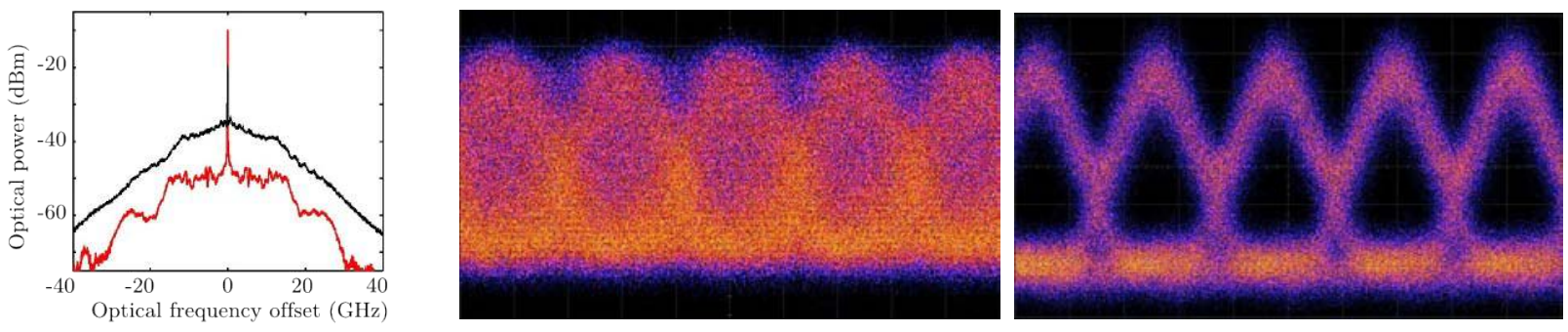

Figure 2:phase chaos cancellation (black: chaotic phase side bands; red: residual side bands after cancellation), and eye diagrams of the encoded and decoded data at 10Gb/s.

\section{Conclusion}

The reported setup has demonstrated its efficiency both in laboratory and field experiments. Successful encoding and decoding of a $10 \mathrm{~Gb} / \mathrm{s}$ DPSK message with a broadband chaotic phase modulation was achieved, over more than $100 \mathrm{~km}$. We expect in the near future that the proposed electro-optic phase chaos architecture can be slightly modified, so that not only hardware analog security can be provided (e.g. through a customized multiple wave imbalanced interferometer), but also through digital key security (when involving dynamical switching of the operating chaotic oscillation, according to a digitally defined switching sequence).

\section{References}

[1] L. M. Pecora and T. L. Carroll, "Synchronization in chaotic systems", Phys. Rev. Lett. 64, 821-824 (1990).

[2] C. R. Mirasso, P. Colet, and P. Garcia-Fernadez, "Synchronization of chaotic semiconductor lasers: Application to encoded communications", IEEE Photonics Tech. Lett. 8, 299-301 (1996).

[3] G. D. VanWiggeren and R. Roy, “Communicating with chaotic lasers",Science 279, 1198-1200 (1998).

[4] A. Uchida, T. Sato, and F. Kannari, "Suppression of chaotic oscillations in a microchip laser by injection of a new orbit into the chaotic attractor",Opt. Lett. 23, 460-462 (1998).

[5] I. Fischer, Y. Liu, and P. Davis, "Synchronization of chaotic semiconductor laser dynamics on subnanosecond time scales and its potential for chaos communication", Phys. Rev. A 62, 011801 (2000).

[6] S. Sivaprakasam and K. A. Shore, "Message encoding and decoding using chaotic external-cavity diode lasers", IEEE J. Quantum Electron. 36, 35-39 (2000).

[7] H. D. I. Abarbanel et al., "Synchronization and Communication Using Semiconductor Lasers With Optoelectronic Feedback", IEEE J. Quantum Electron. 37, 1301-1311 (2001).

[8] K. Kusumoto and J. Ohtsubo, "1.5 GHz message transmission based on synchronization of chaos in semiconductor lasers", Opt. Lett. 27, 989-991 (2002).

[9] A. Argyris et al., "Chaos-based communications at high bit rates using commercial fiber-optic links", Nature (London) 438, 343-346 (2005).

[10] L. Larger, J.-P. Gordegbuer, and V. S. Udalsov, "Ikeda-based nonlinear delayed dynamics for application to secure optical transmission systems using chaos", C.R. De Physique 4 5, 669 (2004).

[11] R. Lavrov et al., "Electro-optic delay oscillator with non-local non linearity: optical phase dynamics, chaos, and synchronization", Phys. Rev. E 80, 026207 (2009). 